\title{
Functional status of skin fibroblasts at chronic staphylococcus aureus osteomyelitis of the tibia
}

\author{
Igor Zhurakovsky, Sergey Arkhypov, Marya Pustovetova, Igor Marinkin, Tatyana Kunts \\ Central Research Laboratory, Novosibirsk State Medical University, Novosibirsk, Russia
}

Email address:

tkunts@ngs.ru(T. Kunts)

\section{To cite this article:}

Igor Zhurakovsky, Sergey Arkhypov, Marya Pustovetova, Igor Marinkin, Tatyana Kunts. Functional Status of Skin Fibroblasts at Chronic Staphylococcus Aureus Osteomyelitis of the Tibia. American Journal of Internal Medicine. Vol. 1, No. 2, 2013, pp. 10-13.

doi: 10.11648/j.ajim.20130102.11

\begin{abstract}
Inflammatory process is not limited only local effects but could affect other organs and tissues. In this study, we investigated the influence of experimental tibial osteomyelitis on skin cells in dynamics. Although the skin located at the distance from the infection nidus it supposed to manifest intensive proliferation, reparation and apoptosis under adverse factors. Immunohistochemical assay of apoptotic regulators and proliferation-related proteins was carried out in fibroblasts of stratum reticulare in Wistar rats. Proliferating fibroblasts pool decrease confirmed by Ki67 expression decrease was revealed, overexpression of p53 and Bax was accompanied by Bcl-2 expression decrease. Findings suggest depressed regeneratory potential of fibroblasts, high probability of apoptosis in the skin cells at the persisting osteomyelitis that should be considered in dermatological practice.
\end{abstract}

Keywords: Osteomyelitis, Tibia, P53, Bax, Bcl-2, Ki-67, Fibroblasts, Stratum Reticulare, Apoptosis, Staphylococcus AUreus

\section{Introduction}

Inflammatory diseases become widespread and affect millions of people leading to pain, disability and, in some cases, death. Many researchers relate the high frequency of chronic diseases in various organs and systems to adverse environmental factors, untimely and inadequate treatment of acute inflammatory processes and immune response to an etiological factor [4, 9, 13]. Long-term course of infection could influence organs and tissues, located away from inflammation nidus that can increase the risk of pathologic changes in certain tissues $[10,12]$. The role of persisting bacterial infection in the initiation and prolongation of apoptosis was demonstrated in the liver [17, 18], however, data concerning these processes in the skin are still lacking. Although the skin does not connected with infection nidus, at first glance, it is supposed to manifest intensive proliferation, reparation and apoptosis under adverse factors effects and certain pathological changes could develop in the skin [7]. In the present study, on the example of apoptotic regulatory proteins (Bcl-2 and Bax) expression and proliferation-related proteins (p53 and Ki67), we investigated the influence of tibia osteomyelitis caused by Staphylococcus aureus on the functional status of fibroblasts in stratum reticulare.

\section{Materials and Methods}

\subsection{Study Design}

The experiment was performed in twenty four male Wistar rats (180-220 g, 2,5 months old). All animals were treated according to protocols approved by the animal care institutional review board. Eighteen rats were subjected the experimental tibia myelitis. Using sterile surgical conditions shin-bone trepanation was carried out under halothane anesthesia, hole was plugged with cotton thread containing Staphylococcus aureus, strain 209 (10 $\left.70^{7} \mathrm{cfu}\right)$. Animals were decapitated 1, 2 and 3-months after surgery. Six intact rats were used as a control.

\subsection{Immunohis to Chemistry}

Specimens were fixed in $12 \%$ formalin and embedded in paraffin. One section was used for the conventional hematoxylin and eosin method. The levels of apoptosis regulators (Bcl-2, Bax, p53) and proliferation marker Ki67 
expression relied on immunocytochemisrty based on indirect streptavidin biotin peroxidase method as described previously [2, 3, 14] according to the manufacturer's instructions. Triton X-100 $(0,1 \%)$ was used for antigen demasking procedure for $5 \mathrm{~min}$. Deparaffinized sections were incubated with primary antibodies: Anti-Bcl-2 (Isotype: Mouse IgG1, Clone: 7; BD Biosciences), AntiBax (Polyclonal Rabbit Anti-Mouse/Rat; BD Biosciences), Anti-Bad (Isotype: Mouse IgG2b, Clone 48; BD Biosciences), Anti-Ki-67 (NCL-MM1, Isotype: Mouse; Novocastra) Anti-p53 (Novocastra NCL-p53-CM5p, Isotype: Mouse $\operatorname{IgG})$. All incubations were performed for $60 \mathrm{~min}$ at room temperature. Immunostaining was performed using Novocastra Peroxidase Detection System (Ready-to-Use) kit (Code No. RE7110-K), which employed the streptavidin-biotin technique and DAB Substrate/Chromogen System for visualization. Cytoplasmic staining for Bcl-2, Bax and nuclear stain for p53 were considered as positive. The expression of oncogenes was determined in 48 non-coincident microscopic fields in each experimental group at $\times 400$ magnification. At least 1000 fibroblasts were evaluated by counting and staining intensity was estimated in area 64500 $\mathrm{mkm}^{2}$ [11]. The data were analyzed quantitatively using Image J $1.42 \mathrm{~g}$ software (National institutes of Health, USA).

\subsection{Data Analysis}

The results were performed as a percentage obtained by the following relationship: $\%$ structure $=\mathrm{S}_{\mathrm{s}} / \mathrm{S}_{\mathrm{t}}, \mathrm{S}_{\mathrm{s}}$ is the stained fibroblasts area and $S_{t}$ is the total investigated area. Results were expressed as the mean $( \pm$ SEM). Statistical analyses were performed using Kruskal-Wallis $\mathrm{H}$ test and Mann-Whitney U test with Bonferroni correction. Statistical significant was accepted at $p \leq 0.05$.

\section{Results}

The localized osteomyelitis model we analysed led to changes in rat health status (fever, appetite loss). After 1 month from the date of inoculation Staphylococcus aureus (Fig. 1, A) necrosis of bone marrow, productive inflammatory process in endosteum and periosteum, osteoclast-mediated bone resorption.

Later on, in 2 and 3 months after inoculation of Staphylococcus aureus bone marrow offered granulation tissue fields bounded the necrosis foci (Fig. 1,B). Bone trabeculae in spongy bone tissue were fragmented, few osteocytes were located irregularly. Focal dispersions could be visualized in bone matrix (Fig. 2).

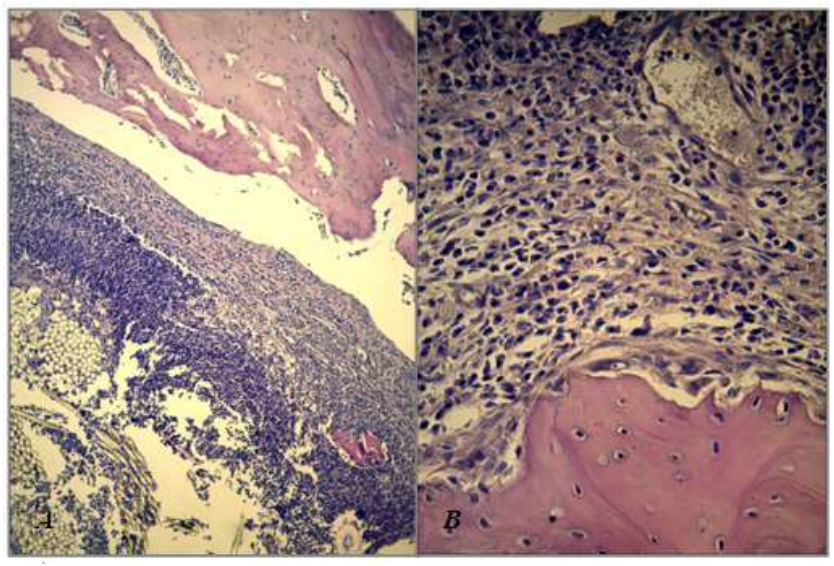

Figure 1. (A) Fragment of rat tibia 1 month after $S$. aureus inoculation. Bone marrow necrosis, osteoclastic bone resorption. (B) Fragment of rat tibia 2 month after $S$. aureus inoculation. Focal necrotic zones are bounded by granulation tissue, osteoclastic bone resorption. Hematoxylin and eosin staining, $\times 400$

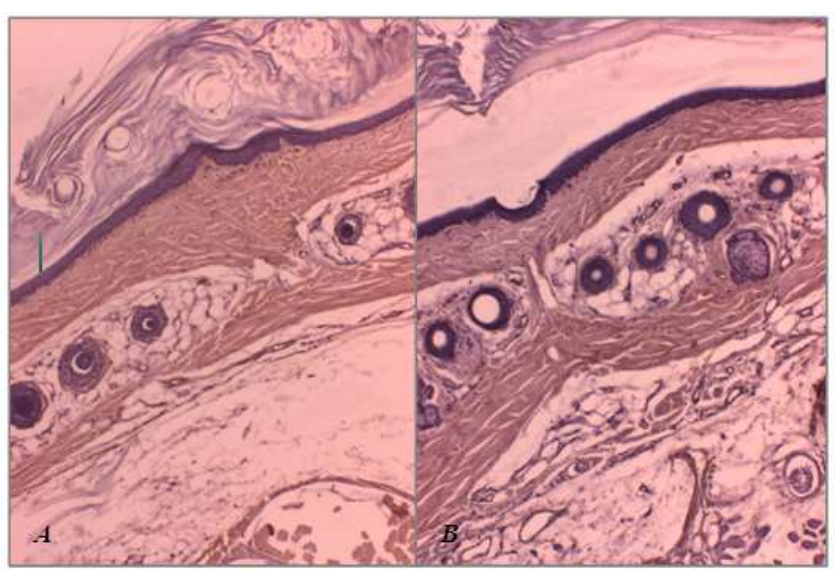

Figure 2. (A) Rat skin 2 month after S. aureus inoculation. Disturbance of collagen compact order in stratum reticulare. (B) Rat skin 3 month after $S$. aureus inoculation. Disturbance in compact order and tinctorial properties of collagen. Hematoxylin and eosin staining, $\times 100$

The most of skin objects 1 month after persisting infection nidus have been produced didn't vary from the control. However, disturbances in compact arrangement of collagenous fibers and empty spaces between separate fibers were revealed in stratum reticulare. Subsequently, morphological investigation of rat skin found out not only aggravation of disturbances in collagen elements order (Fig. 3 , A) but also changes in tinctorial properties of collagen (Fig. 3, B).

The molecular analysis for p53 gene revealed that there was no statistically significant difference in the intensity in investigated area 1 month after modeling of distant chronic inflammation nidus. However, the area of cells expressing Bax was increased by 2,4 times (Table 1) along with decrease of specific staining intensity that was an evidence of stratum reticulare fibroblasts population growth. The intensity of Bcl-2 staining and the area of dermal fibroblasts expressing Ki67 were decreased. 
Table 1. Area relative (\%) and staining intensity (standard units) of marker-expressing fibroblasts, mean \pm SEM

\begin{tabular}{ccccc}
\hline \multirow{2}{*}{ Variable } & Control & \multicolumn{3}{c}{ Inflammation } \\
& & 1 Month & 2 мonth & 3 мonth \\
\hline \multicolumn{2}{c}{ area relative } & & & \\
Bcl-2 & $3,46 \pm 0,21$ & $3,77 \pm 0,20$ & $2,32 \pm 0,11^{*}$ & $1,74 \pm 0,07^{*}$ \\
Bax & $0,33 \pm 0,03$ & $0,78 \pm 0,04^{*}$ & $1,27 \pm 0,12^{*}$ & $2,15 \pm 0,10^{*}$ \\
p53 & $0,80 \pm 0,04$ & $1,00 \pm 0,07$ & $1,31 \pm 0,10^{*}$ & $1,97 \pm 0,10^{*}$ \\
Ki67 & $1,29 \pm 0,06$ & $0,91 \pm 0,06^{*}$ & $0,84 \pm 0,06^{*}$ & $0,54 \pm 0,05^{*}$ \\
staining intensity & & & \\
Bcl-2 & $51,24 \pm 1,74$ & $33,90 \pm 0,84^{*}$ & $54,39 \pm 0,87$ & $61,06 \pm 0,71 *$ \\
Bax & $68,94 \pm 1,55$ & $56,05 \pm 1,53^{*}$ & $50,21 \pm 0,91^{*}$ & $51,91 \pm 1,79^{*}$ \\
p53 & $60,54 \pm 2,02$ & $57,22 \pm 1,53$ & $60,71 \pm 1,30$ & $46,87 \pm 1,50^{*}$ \\
Ki67 & $51,79 \pm 1,50$ & $56,91 \pm 1,25^{*}$ & $75,50 \pm 1,09^{*}$ & $53,83 \pm 1,91$ \\
\hline
\end{tabular}

* - p $<0,05$ compared to control

The analysis of the p53 expression in cellular elements of stratum reticulare revealed 1,6 times raising 2 months after chronic inflammation onset (Table 1; Fig. 4, B) compared to intact animals. We also found out further rise of area of Bcl-2-expressing fibroblasts. Expression level of Bax was increased 3,85 times (Table 1, Fig. 4, A). A 1,5-fold reduction of Ki67-expressing fibroblasts area was typical for this period. p53 protein is known to be retarding the mitotic activity in normal cells [16]. Some stimulus such as hypoxia turns the cell to apoptosis by p53 gene activation. p53 stops the cell in the phases $\mathrm{G} 1$ and $\mathrm{S}$ through the repression transcriptional regulation, interacts with complexes participating in synthesis and reparation of DNA or apoptosis modulating proteins. If the damage is not repaired p53 triggers apoptosis through inactivation of Bcl2 that binds $\operatorname{Bax}[1,8,15]$.

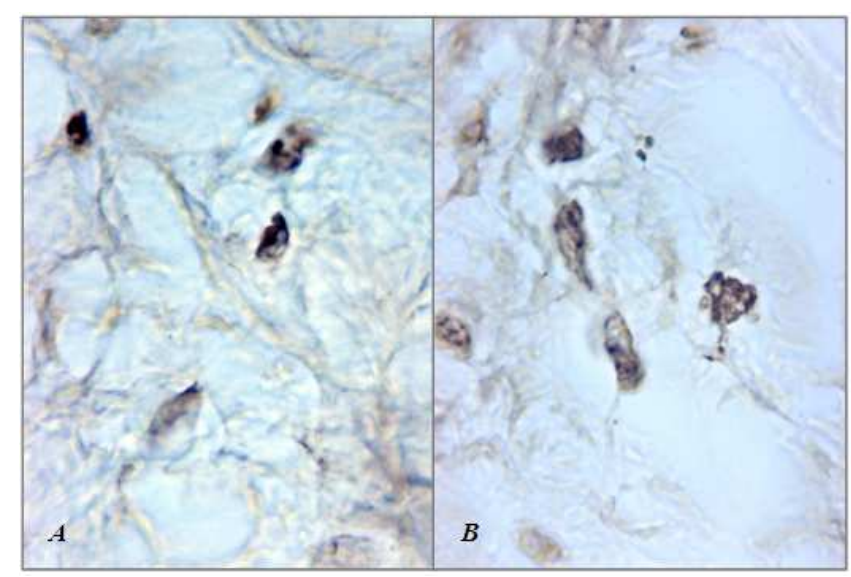

Figure 3. Rat stratum reticulare 2 month after Staphylococcus aureus inoculation, Immunostaining for Bax-expressing (A) and p53-expressing (B) cell elements, $\times 1000$

3 months after bacterial infection nidus formation progressing increase of $\mathrm{p} 53$-expressing cells was revealed (Table 1; Fig. 5, B). The area of stratum reticulare fibroblasts expressing Ki67 reduced in 2,4 times. The area of Bcl-2-expressing cellular elements became progressively smaller.

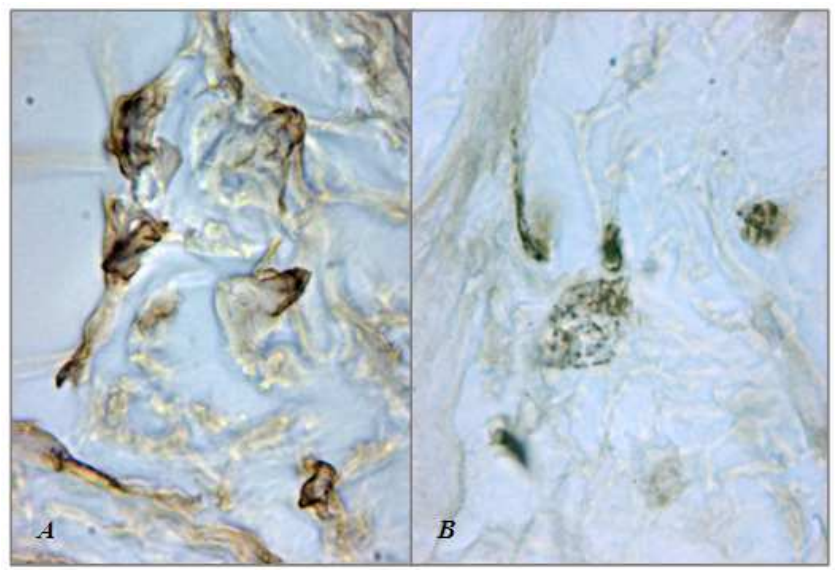

Figure 4. Rat stratum reticulare 3 month after Staphylococcus aureus inoculation. Immunostaining for Bax-expressing (A) and p53-expressing (B), cell elements, $\times 1000$

Considering Bax protein, our study inferred significant decrease of its specific staining of fibroblasts although the area of cells expressing this marker was greater in 6,5 times compared to a control (Table 1; Fig. 5, A). It is known that Bcl-2 and Bax are in permanent balance and form homoand heterodimers [6]. If production of Bax protein predominates the balance drifts to homodimers forming that possess high proapoptogenic activity [5].

\section{Conclusion}

The study has shown that inflammatory process is not limited only local effects but could affect the distant tissues, for example, the skin. Analysis of apoptotic regulators and proliferation-related proteins expression revealed increased probability of apoptosis in fibroblasts of stratum reticulare at persisting staphylococcal infection in the tibia. Proliferating fibroblasts pool decrease confirmed by Ki67 expression decrease and also expression increase of p53 were found out. Moreover, concerning proapoptotic protein Bcl-2 rise we suppose it probably binds to Bcl-2 that allows apoptosis activation at depressed regeneratory ability of fibroblasts. Changes in skin cellular elements investigated at the distant bacterial infection nidi are should be considered in dermatological practice.

\section{References}

[1] R. S. Akhtar, Y. Geng, B. J. Klocke, K. A. Roth, "Neural precursor cells possess multiple p53-dependent apoptotic pathways ", Cell Death Differ., 2006, vol. 13, pp. 1727-1739.

[2] S. A. Arkhipov, V. A. Shkurupy, M. V. Solomatina, E. S. 
Akhramenko, D. A. Iljine, "Study of macrophages in BCG granulomas in different compartments of the mononuclear phagocyte system", Bull. Exp. Biol. Med., February 2013, vol. 154 (4), pp. 467-470.

[3] F. Bibeau, F. Boissière-Michot, J. C. Sabourin, “Assessment of epidermal growth factor receptor (EGFR) expression in primary colorectal carcinomas and their related metastases on tissue sections and tissue microarray", Virchows Arch., 2006, vol. 449 (3), pp. 281-287.

[4] O. V. Bukharin, "Significance of bacterial pathogens persistence for clinical practice", Russ. Med. News, 2000, vol. 5 (3), pp. 18-25.

[5] C. Franke, M. Nöldner, R. Abdel-Kader, L. N. JohnsonAnuna, W. Gibson Wood, W. E. Müller, G. P. Eckert, "Bcl-2 upregulation and neuroprotection in guinea pig brain following chronic simvastatin treatment", Neurobiol. Dis., 2007, vol. 25 (2), pp. 438-445.

[6] B. N. Green, C. D. Johnson, J. T. Egan, M. Rosenthal, E.A. Griffith, M. W. Evans, "Methicillin-resistant Staphylococcus aureus: an overview for manual therapists", J. Chiropr. Med., 2012, vol. 11 (1), pp. 64-76.

[7] M. Jarvis, U. Schulz, A. M. Dickinson, L .Sviland, G. Jackson, A. Konur, X. N. Wang, I. Hromadnikova, H. J. Kolb, G. Eissner, E. Holler, "The detection of apoptosis in a human in vitro skin explant assay for graft versus host reactions", J. Clin. Pathol., Feb 2002, vol. 55, pp. 127-132.

[8] S. L. Harris, A. J. Levine, "The p53 pathway: positive and negative feedback loops", Oncogene, 2005, vol. 24. pp. 2899-2908

[9] V. A. Karpin, "General pathology: chronic infectious process”, Succes. Nat. Sc., 2005, vol. 4, pp. 17- 20.

[10] P. J. Lindsberg, A. J. Grau "Inflammation and infections as risk factors for ichemic stroke", Stroke, 2003, Oct, vol. 34, pp. 2518-2532.

[11] Mathieu, L. M. Cruz-Orive, H. Hoppeler, E. R. Weibel "Measuring error and sampling variation in stereology: Comparison of the efficiency of various methods of planar image analysis", J. Microsc., 1981, vol. 121 (1). pp. 75-88.

[12] T. J. Pallasch, M. J. Wahl, "The focal infection theory: appraisal and reappraisal”, J. Calif. Dent. Ass., 2000, vol. 28 (3), pp. 194-200.

[13] N. A. Pecareva, L. A. Trunova, T. V. Belousova, O. M. Gorbenko, A. P. Shvayuk, A. N. Trunov, "About activity of immune-inflammation in children with chronic pyelonephritis in clinical remission", Bull. Russ. Acad. Med Sc., 2008, vol. 131 (3), pp. 52-55.

[14] J. A. Ramos-Vara, "Technical Aspects of Immunohistochemistry", Vet. Pathol., 2005, vol. 42 (4), pp. 405-426.

[15] M. Schuler, D. R. Green, "Transcription, apoptosis and p53: Catch-22", Trends Genet., 2005, vol. 21, pp. 182-187.

[16] J. Yu, L. Zhang, "The transcriptional targets of p53 in apoptosis control", Biochem. Biophys. Res. Commun., 2005, vol. 331 , pp. 851-858.

[17] P. Zhurakovsky, S. A. Arkhipov, M. G. Pustovetova , T. A. Kunts, M. V. Bitkhaeva, I. O. Marinkin, "Activation of mitochondrial way hepatocyte apoptosis when the persistence of bacterial infection", Zabaik. Med Bull., 2011, vol. 2, pp. 125-131.

[18] P. Zhurakovsky, S. A. Arkhipov, M. G. Pustovetova, T. A. Kunts, M. V. Bitkhaeva, I. O. Marinkin, "Bcl-2 expression changes in rat liver and cytokines levels in blood serum at the persistence of a bacterial infection", Kuban. Med. Sc. Bull., 2012, vol. 2, pp. 84-88. 